\title{
An Integrated Literature Review of Death Education in Pre-Registration Nursing Curricula: Key Themes
}

\author{
Joyce Cavaye ${ }^{1}$ and Jacqueline H. Watts ${ }^{2}$ \\ ${ }^{1}$ Faculty of Health \& Social Care, The Open University in Scotland, 10 Drumsheugh Gardens, Edinburgh EH3 7QJ, UK \\ ${ }^{2}$ Faculty of Health \& Social Care, The Open University in London, 1-11 Hawley Crescent, Camden Town, London NW1 8NP, UK \\ Correspondence should be addressed to Jacqueline H. Watts; jackie.watts@open.ac.uk
}

Received 29 May 2013; Accepted 3 September 2013; Published 2 January 2014

Academic Editors: L. Deliens, C. Knapp, S. Mcilfatrick, P. J. Newton, and M. O’Connor

Copyright (c) 2014 J. Cavaye and J. H. Watts. This is an open access article distributed under the Creative Commons Attribution License, which permits unrestricted use, distribution, and reproduction in any medium, provided the original work is properly cited.

Recent policy has raised the profile of end-of-life care internationally, with the aim of increasing access to quality care for everyone experiencing life-limiting illness. This reflects an international shift in the provision of palliative care to encompass chronic conditions other than cancer. Nurses have an important role in delivering this care and need to be equipped with particular knowledge and skills. However, pre-registration nursing curricula have traditionally had a limited emphasis on death and dying and nurses report feeling unprepared to care for dying patients. This has led to claims that death education in pre-registration curricula is inadequate. This integrated review explores the published literature that reports on death education within pre-registration nurse education. Presenting an international overview, the aim of the review is to contribute to knowledge about the nature and extent of death education in pre-registration curricula. In the context of this paper, death education encompasses both palliative and end-oflife care. Electronic searches of major bibliographic databases found inconsistencies across educational provision with variations in quantity, content, and approach. Despite an increasing amount of death education in pre-registration curricula, there remains a deficit in key areas such as knowledge, skills, organisation of care, and teamwork.

\section{Introduction}

The World Health Organization [1] issued a directive that all individuals dying from life-limiting illness are entitled to quality care across a range of settings when approaching death.

Policy initiatives across the world have sought to respond to this directive which essentially calls for a change in culture around palliative and end-of-life care. In Europe, a number of organisations, collaborating under the auspices of the European Association for Palliative Care (EPAC) Task Force, have published several evidence-based reports which seek to influence the development of palliative care policy and practice across Europe [2]. The Eurobarometer Survey, a major qualitative study developed to gather the views of key palliative care leaders, collated information on the current state of palliative care, and the barriers to and opportunities for development of palliative care across 52 countries of the WHO European region. Developed by the EPAC Taskforce on the Development of Palliative Care in Europe, the Eurobarometer Survey found that lack of education and training opportunities are major barriers to the development of palliative care in Western Europe [3]. It reported that in undergraduate and postgraduate curricula for all healthcare professionals in Austria, Belgium, Finland, Greece, Italy, Israel, Malta, Norway, and Luxembourg there is a lack of palliative care content [3]. While in France, the goal of the national palliative care development programme implemented in 2008, is to develop home and hospital palliative care services and it includes a focus on education for all health care workers [4]. An End of Life Care Strategy with similar intent has also been published in the United Kingdom (UK) [5, 6]. It claims that healthcare managers often fail to recognise that providing care for dying patients is one of their core functions; hence, staff are not provided with education in this area [5]. The UK End of Life Strategy, thus, advises that care of the dying should be embedded in nurse education at all stages [5]. 
In Canada, the recent strategy on palliative care underpins structural change in service delivery and sets out a wide ranging agenda to achieve quality outcomes for those approaching the end of their life regardless of the care setting [7]. Policy in the United States (US), Ireland, and Australia, has also focused on the development of care standards [811] and improving the quality of teaching on nursing programmes. For example, the End-of-Life Nursing Education Consortium (ELNEC) in America was established in 2000 in order to improve end-of-life expertise in educators teaching on undergraduate nursing programmes [12, 13]. More recently, the Prague Charter urges governments around the world to implement health care policies that "will ensure the relief of suffering through adequate access to patient-centred palliative care wherever it is needed" and that "failure to provide palliative care can constitute cruel, inhumane, or degrading treatment" [14, page 101]. The Charter acknowledges the need for changes in the undergraduate curricula for all health care professionals to ensure that within their training, they acquire a basic knowledge of palliative care and are, therefore, better equipped to deliver it [14].

The ambitious policies outlined above identify death and dying as a vital and integral part of palliative care. They also reflect an international trend, whereby palliative care that has been associated with cancer, now focuses more widely on other conditions such as multiple sclerosis, dementia, and motor neurone disease $[13,15]$. The WHO [16] estimates that 36 million deaths in 2008 were due to noncommunicable diseases, such as cancer or cardiovascular disease. The majority of patients with these conditions die without adequate pain or symptom control and most lack access to psychological and spiritual support $[13,14]$. For these patients and their families, palliative and end-of-life care are essential.

The main aim of international policies referred to above is to influence healthcare practice to ensure that everyone approaching the end of life experiences a "good death". Enhancing educational provision about death and dying that informs care practice is central to the success of these recent policy initiatives. In this respect, nurses typically spend the most time with dying patients and provide physical and psychological care throughout the lifespan and in a variety of healthcare settings. Yet, for many student nurses, providing end-of-life care is challenging and a source of stress during clinical placements $[17,18]$. Many students express the concern that their education has inadequately prepared them to care for dying patients [17, 19-22].

A number of reports document the inadequacies in knowledge, skills, and education of nurses [12, 13, 23, 24]. Writing about the UK system, Becker [25] draws attention to how few standards within pre-registration programmes positively engage with death education and claims that despite the UK End of Life Care Strategy, educational opportunities are declining [25]. Since 2011, all pre-registration nursing programmes in the UK are required to comply with practice competencies identified by the Nursing and Midwifery Council (NMC). Yet, from 34 new practice competencies, palliative care is mentioned in only three [26]. Furthermore, the theoretical frameworks within which programmes are delivered contain 10 standards in which end-of-life care is alluded to in only one [27]. However, in some countries such as Germany [3] and Argentina [23], standards differ and death education is not a mandatory element of the undergraduate pre-registration curriculum.

Although all nurses will face the death of a patient, historically, nurse education has failed to directly address issues of death in the pre-registration curriculum [22, 28-30]. Quint's [28] landmark study was the first to highlight a lack of both didactic education and clinical experience of death and dying during nurse training. She argues that nursing students exposed to death without appropriate education develop anxiety and negative attitudes and eventually limit their involvement in the care of dying patients. While Quint's work subsequently encouraged the inclusion of death education in curricula, more recent concerns focus on the amount of death education and nurses' preparedness to care for dying patients $[31,32]$. Allchin [22], thus, comments that nurse educators for more than thirty years have been calling for a greater emphasis in nurse education on the topics of death and dying, with this lack reflected in the quality of care provided [20, page 305].

The aim of the review is to contribute to the knowledge about the nature and extent of death education in preregistration curricula. Death education is the term used in this paper to encompass both palliative and end-oflife care. While these terms essentially pertain to discrete phases in the illness trajectory, the transition may not be clearly identified and nurses providing palliative care will also encounter dying patients. Palliative and end-of-life care are, therefore, inextricably linked and this perhaps explains why much of the literature uses these terms interchangeably. The emphasis of the discussion below is on the quantity, content, and reported outcomes of educational provision on prequalifying programmes. The discussion is set against the background of developments in nurse education $[33,34]$, the challenges facing nurse educators [35], the increasing provision of specialised palliative care education for postqualified nurses [36], and a continuing concern about the lack of specific practitioner skills in end-of-life care [37, page 60], $[3,24,38]$.

\section{Methods}

This review used an integrative approach. According to Russell [39], an integrative literature review helps researchers to maintain a knowledge base in a particular area of practice or research. It offers a strategy to search for and assess what is known about a particular topic with a view to identifying central issues in a particular area or suggesting directions for future research [39]. An integrated review of the literature is defined by Cooper [40, page 47] as one where "past research is summarised by drawing overall conclusions from many studies." By systematically analysing and summarising the literature, an integrated review can identify gaps in the current knowledge and the need for further research [39]. In order to enhance rigour in the review, the five-stage approach proposed by Whittemore and Knafl [41] was used and is outlined in Table 1. 
TABLE 1: Integrative review process.

(1) Problem identification

(2) Literature search

(3) Data evaluation

(4) Data analysis

Den

(5) Presentation (results)
What is the nature and extent of provision of death education end-of-life care/palliative care in pre-registration curricula?

Electronic databases searched: ONCL First Search, ASSIA, Psychlnfo, CINAHL, MEDLINE, EMBASE, British Nursing Index, and AMED

Data included theoretical and empirical reports. Quality evaluation by two researchers

Qualitative analysis to develop themes and categories

Quantity: amount and perceived adequacy

Content and teaching strategies: the interventions used in curricula design

Reported outcomes: attitudes, communication, and clinical skills

Limitations: stringent inclusion criteria including exclusion of papers focusing on postregistration education

Data quality of included papers: small numbers, incomplete data sets, and tendency towards self-reporting
2.1. Problem Identification. In this review, death education is a broad term used to define educational modules or courses that include end-of-life and palliative care components that address issues relevant to the care of dying patients. Recent policy aims to increase the quality of and access to quality care for everyone living with and dying from life-limiting illness. This has implications for the education and training of nurses who need to be equipped with particular knowledge and skills in order to deliver this care. However, empirical studies in the past two decades related to death education, including palliative and end-of-life care, have focused predominantly on postregistration educational programmes. There is a paucity of information on the nature and extent of provision on preregistration programmes. Pre-registration nurse education is defined as an undergraduate programme of theoretical and practical training that, on successful completion, leads to eligibility to register to practise as a professionally qualified nurse. The purpose of the review was, therefore, to explore the published literature that reports on death education within pre-registration nurse education. The aim of the review is to contribute to the knowledge about the nature and extent of death education in pre-registration curricula.

2.2. Literature Search. Sampling the literature is essential to enhance rigour in an integrative review [41]. In this review, key search terms included "student nurse," "death and dying," "end-of-life care", "palliative care," "nurse education," "pre-registration," and "pre-registration curricula" and combined Boolean search terms "and" and "or." The search explored eight electronic databases: ONCL First Search, ASSIA, Psychlnfo, CINAHL, MEDLINE, EMBASE, British Nursing Index, and AMED and was extended by scanning reference lists of located papers for pertinent articles and by hand searches of the most recently published editions of key journals.

The search was limited to papers written in the English language and published between 1990 and 2013. Certain seminal papers pre-1990 which evidenced the development of death education in pre-registration nursing programmes, were also included. The review also used inclusion and exclusion criteria to select the relevant literature. Inclusion criteria were papers reporting on primary and secondary research relating to: student nurses or a multidisciplinary group of health professionals including nurses, undergraduate preregistration modules, and content and outcomes of nurse education programmes about palliative, end-of-life, or cancer care. Policy documents, grey literature, and best practice reports were excluded. In the last category articles focusing on patients, registered nurses, non-nursing students, and other healthcare staff, though of potential interest, were outside the designated criteria and, as such, were excluded.

The authors of this article independently scrutinised the title and abstracts of each article. Papers which met the inclusion criteria were read and checked against the inclusion criteria. The decisions were discussed and agreement was reached on the final selection of articles to be included. From the possible 116 articles identified, 41 met the inclusion criteria and are included in the review. These articles originated from the UK, USA, South America, Canada, Australia, Europe, and SE Asia. Table 2 provides detailed information about the design and methodology of studies included.

2.3. Data Evaluation. Whittemore and Knafl [41] claim that when carrying out an integrative review, the quality of the data is central to the process. They advise that, where papers use similar research designs, a simple scoring system should be used to allow comparisons between studies. As this review included papers with a wide range of research methods, literature was coded according to two criteria as recommended by Whittemore and Knafl [41]: methodological or theoretical rigour and data relevance on a 2-point scale (high or low). Thus, the quality evaluation of selected papers was undertaken independently, decisions discussed, and agreement reached on the final selection of the literature to be included. Whilst all studies are culturally specific, the findings are informative because of their resonance with the experience of educators in other countries.

2.4. Data Analysis. Whittemore and Knafl [41] have suggested that strategies for data analysis in integrative reviews are poorly developed. In this review, qualitative content analysis was used [42]. This involved reading and rereading the papers and preparing a short descriptive summary (Table 2). Codes were generated to enable the findings to be compared within and between the papers. Each paper was analysed 


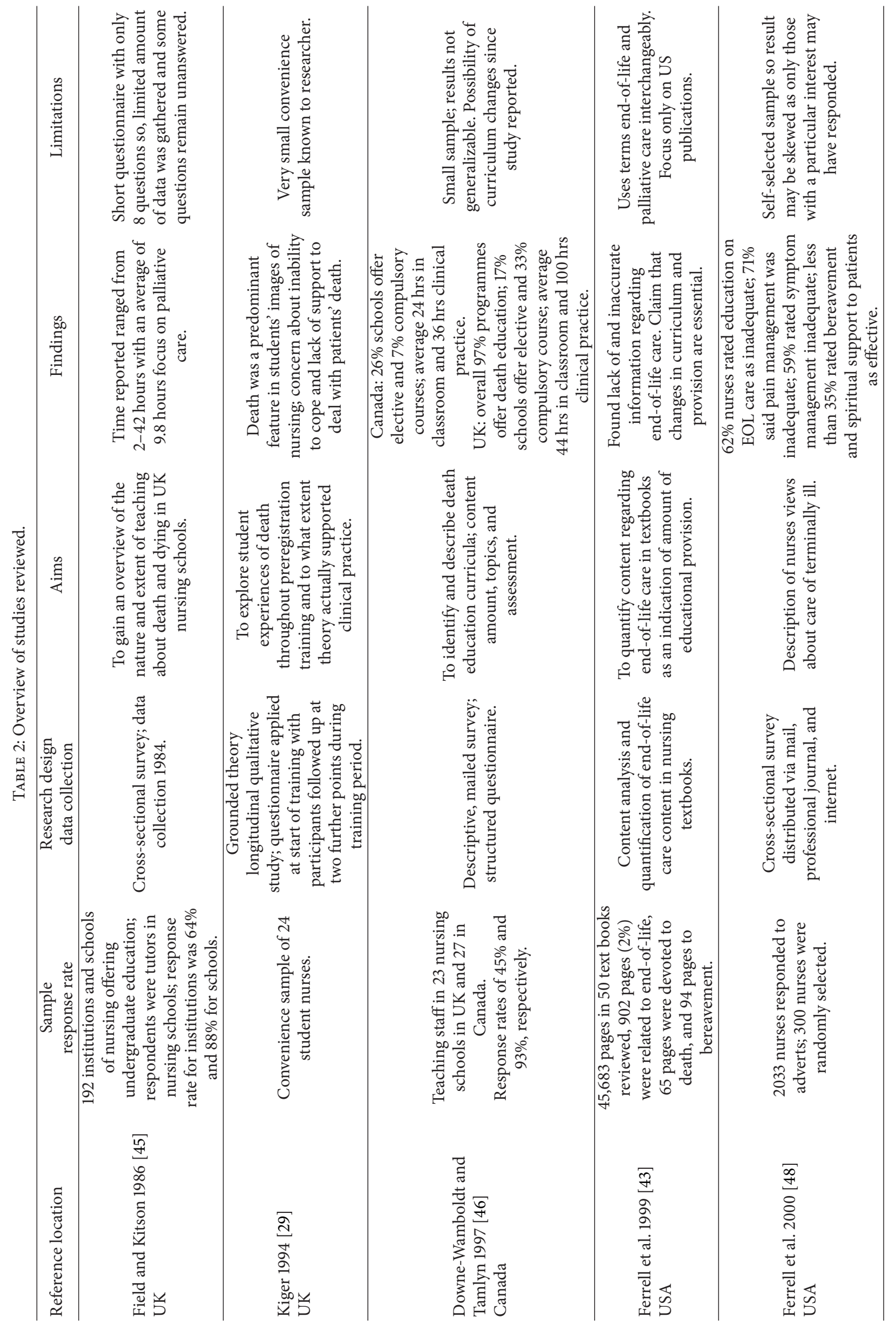




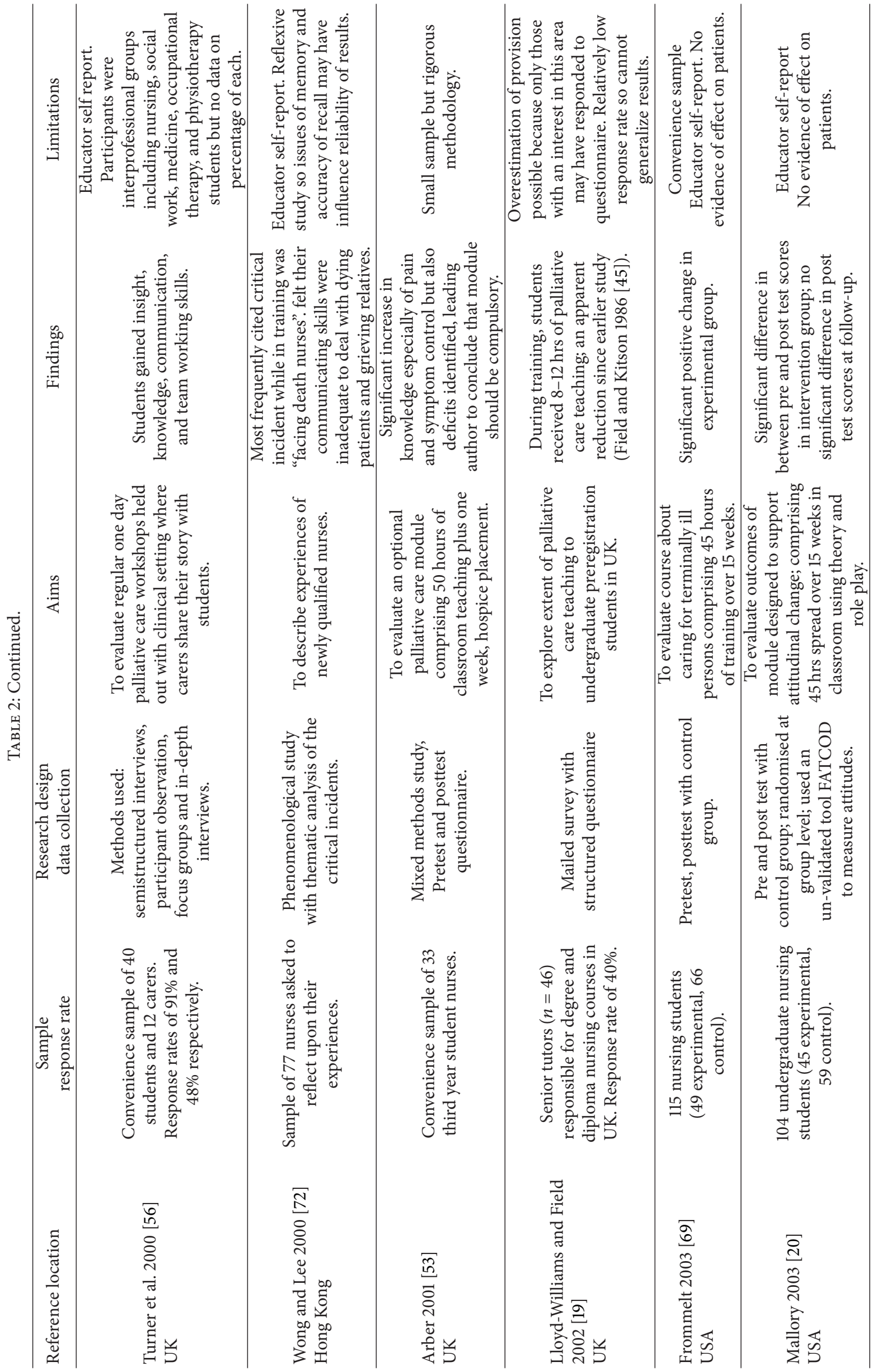




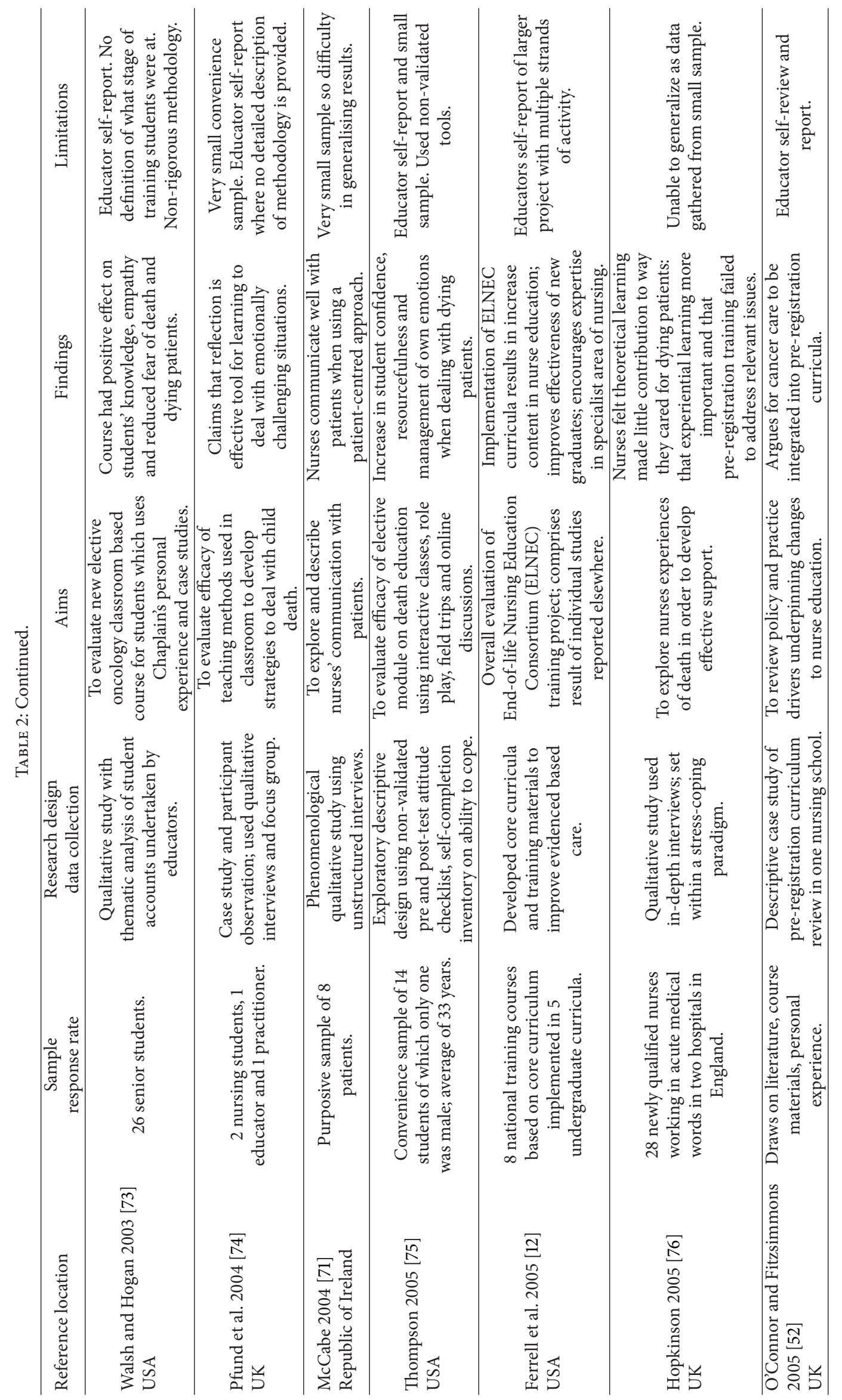




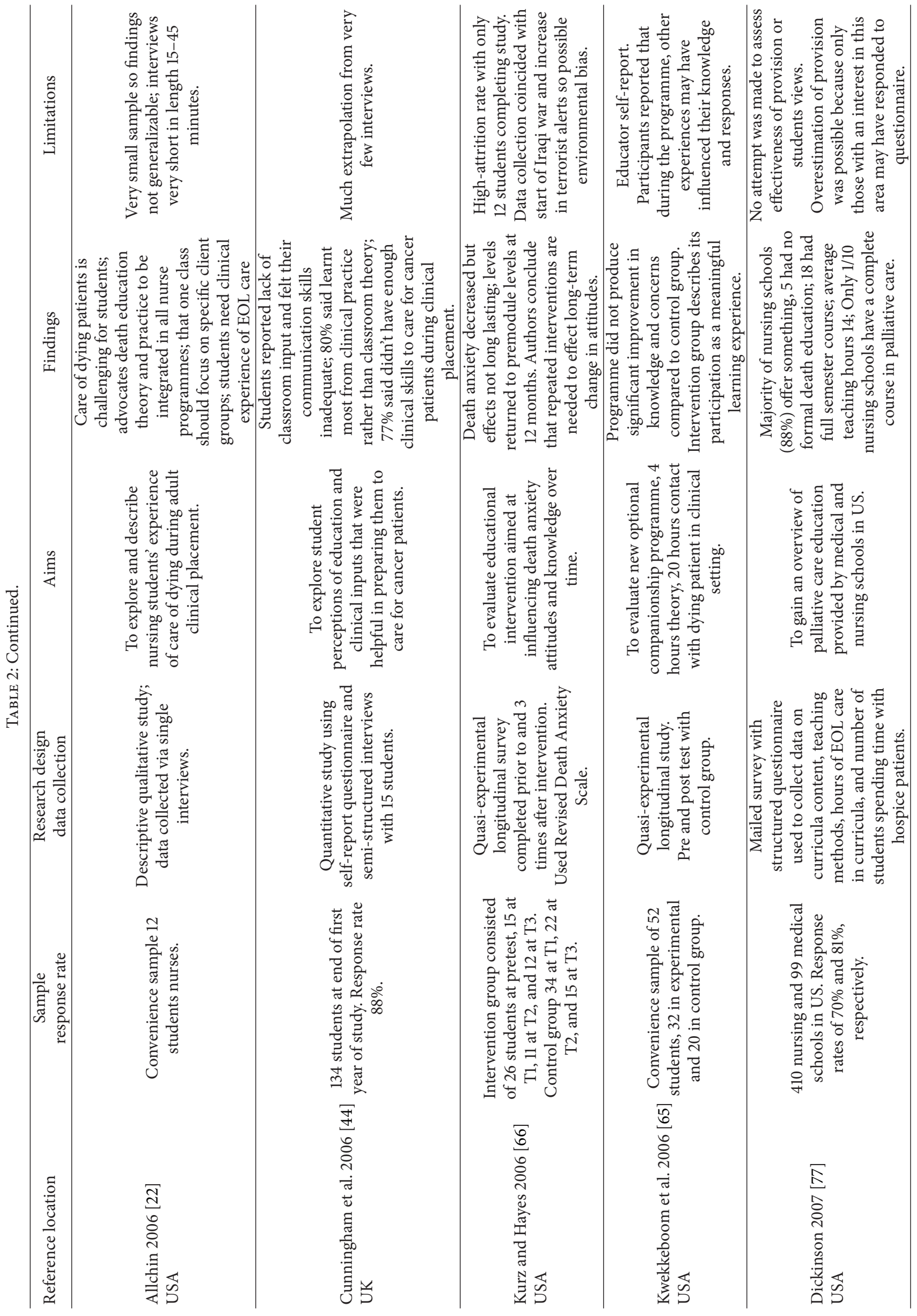




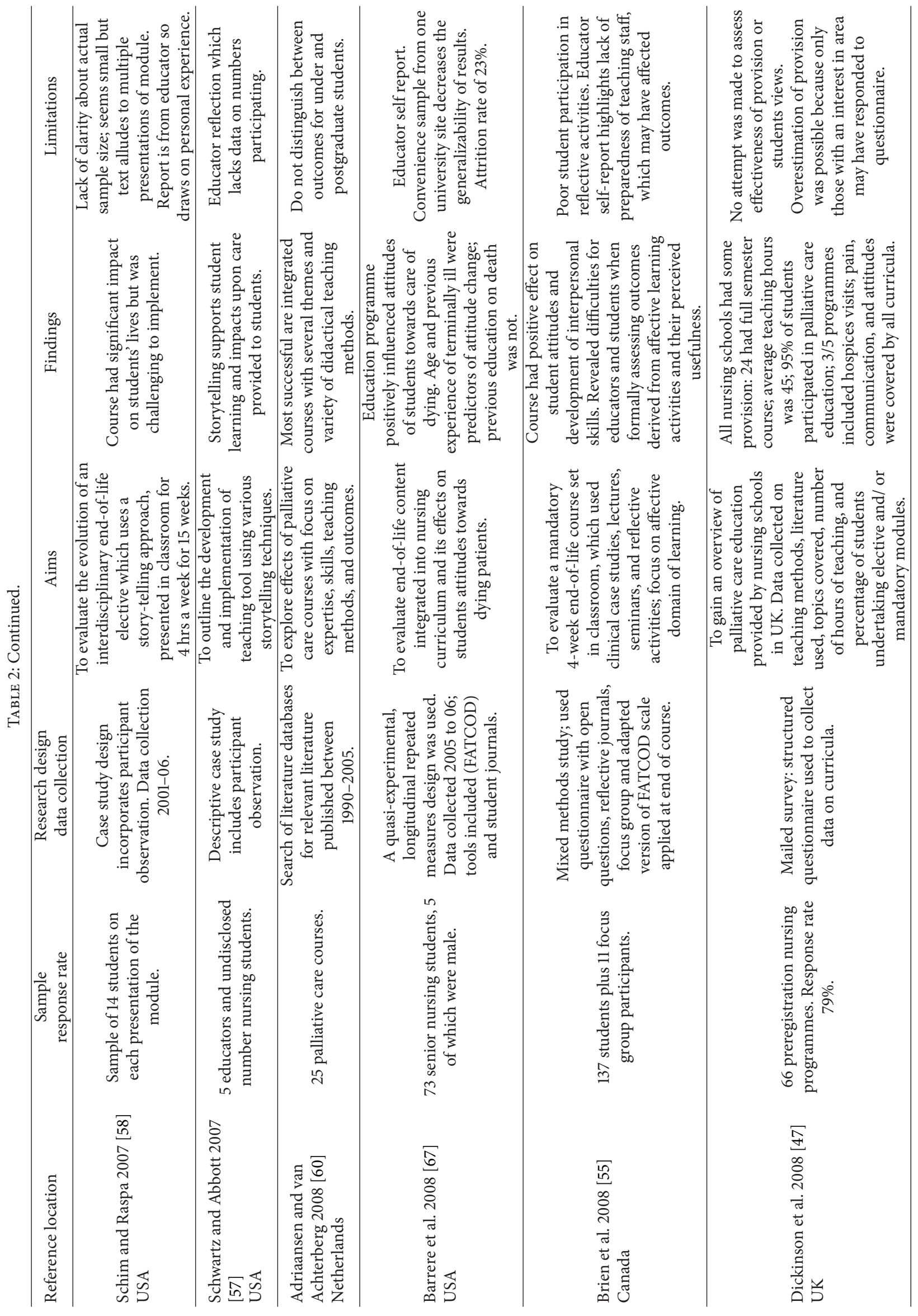




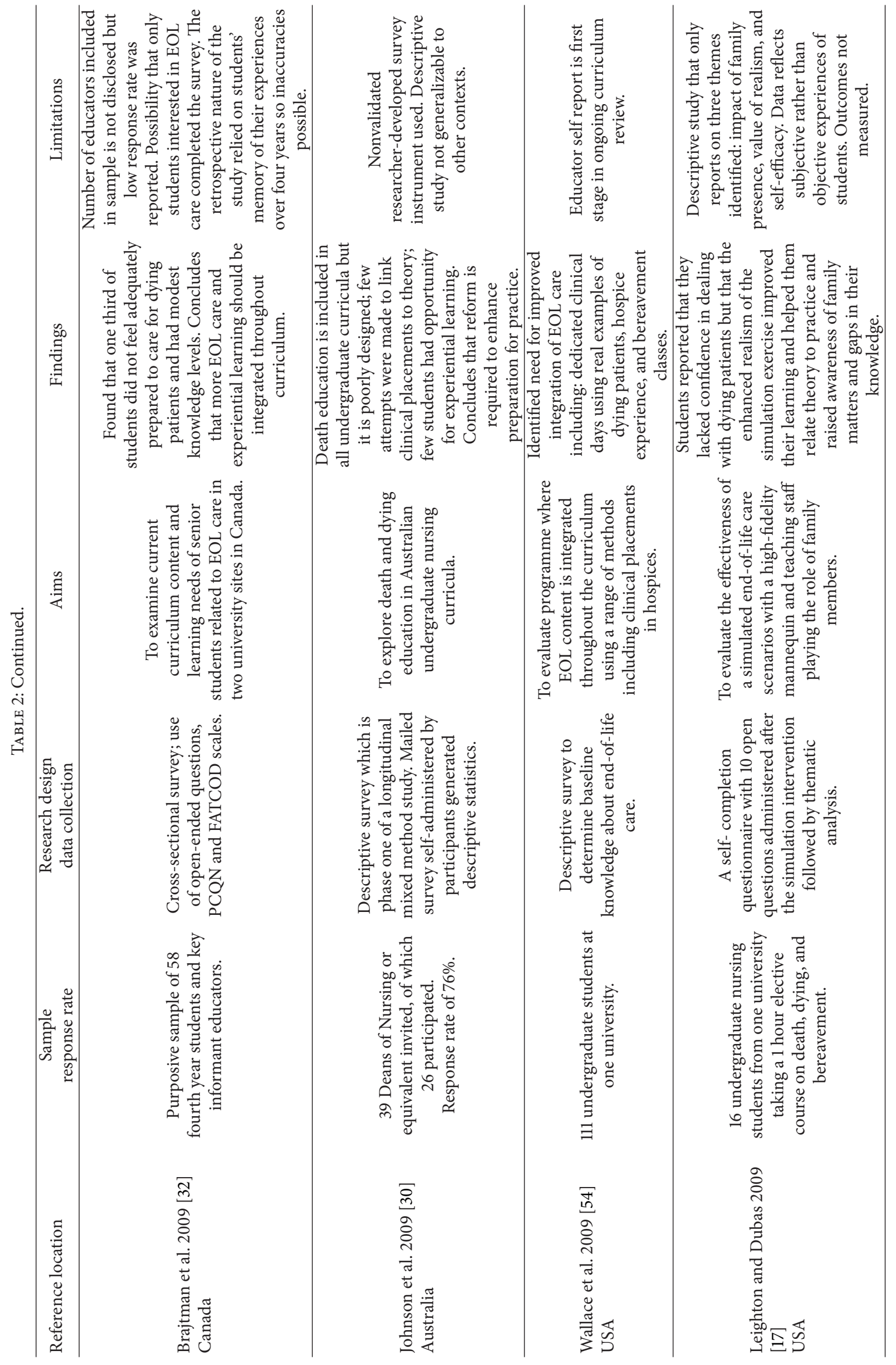




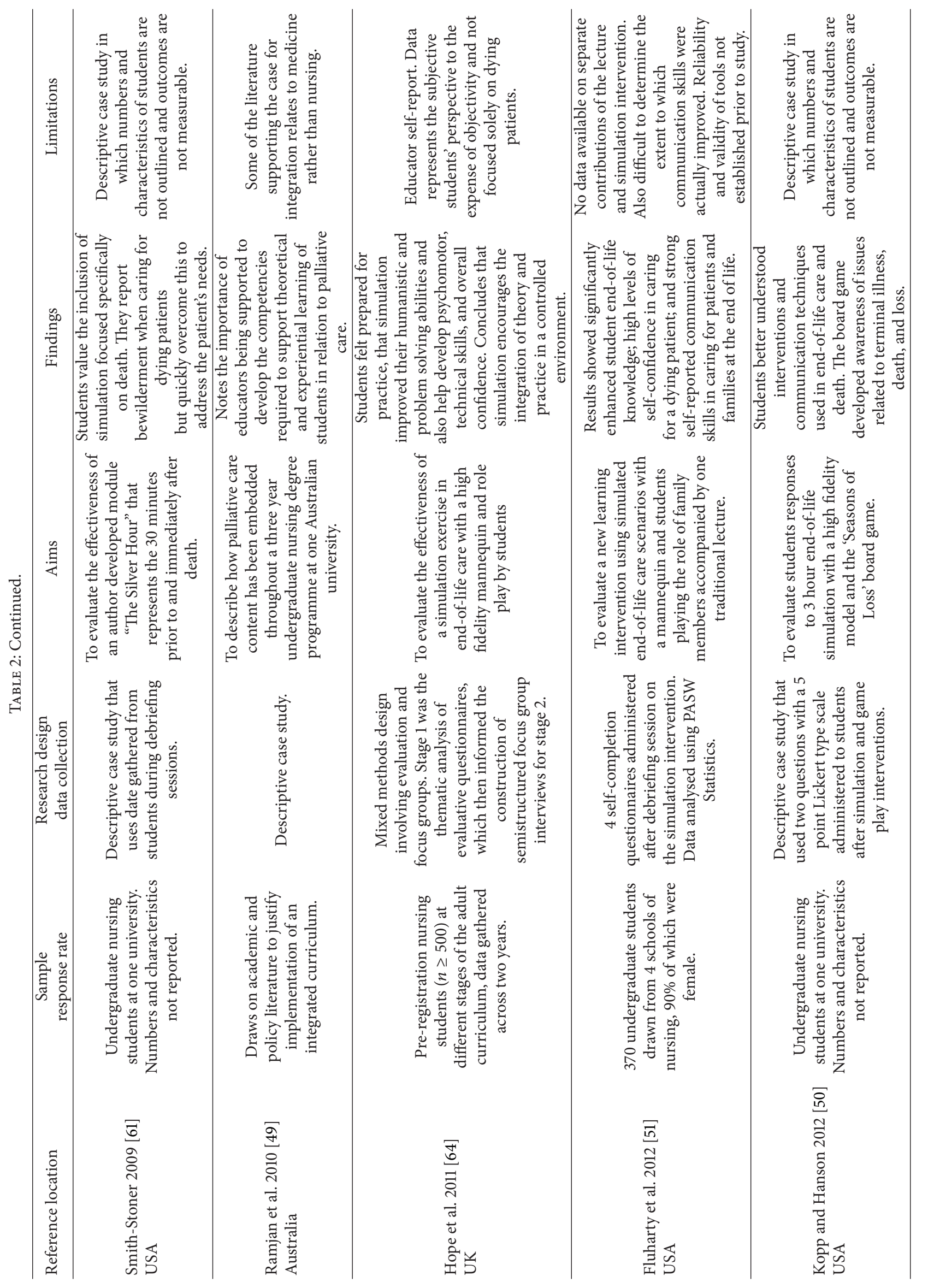




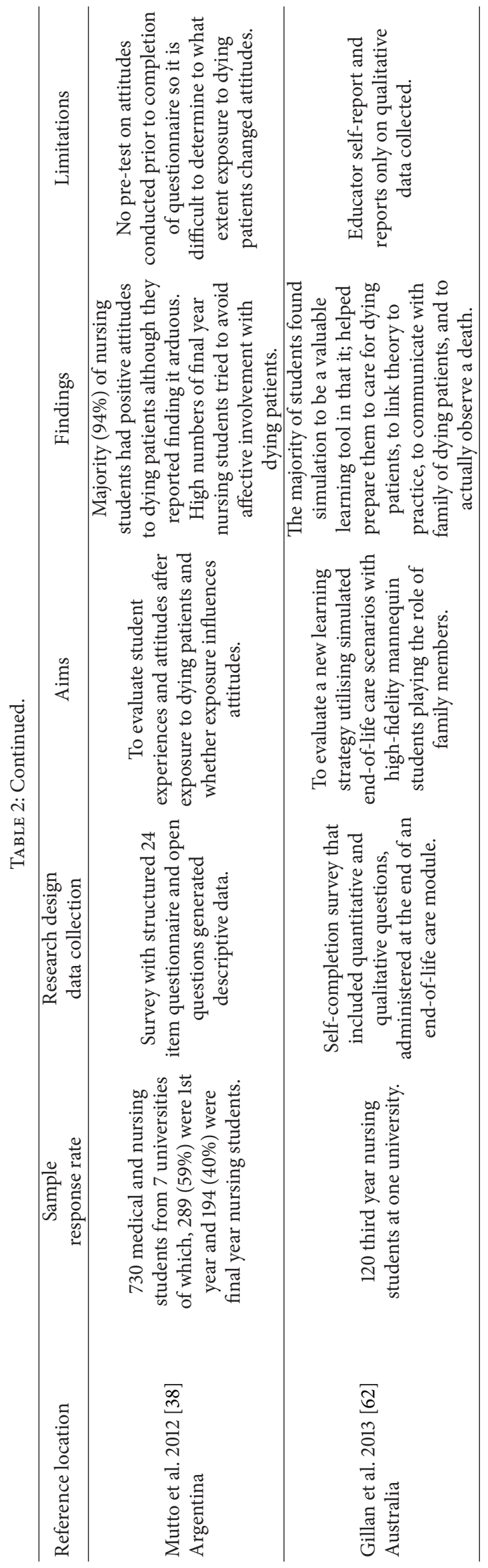


by two reviewers and the codes agreed through review and negotiation.

2.5. Results. Three broad themes emerged from the analysis: the quantity of death education included in pre-registration curricula, the content and teaching strategies used, and the reported outcomes from these interventions. These are discussed in more detail in the following sections.

\section{Amount of Death Education in Curricula}

A total of seven studies addressed the amount of death education in pre-registration curriculum. Reviewers of death education for nurses have over the last two decades, consistently cited inadequacies of provision [30, 43, 44], but evidence of the amount delivered is inconsistent. Field and Kitson's [45] survey, for example, found that while the majority of nursing schools in the UK included some death education within their pre-registration curricula, only an average of 9.8 hrs was devoted to it. An increase in the amount delivered was detected by Downe-Wamboldt and Tamlyn's [46] survey (response rate $45 \%$ ) which found that $97 \%$ of the programmes in the UK offer death education with an average of 44 hours of classroom tuition and 100 hours of clinical practice. These findings are contradicted by Lloyd-Williams and Field's [19] study of senior nurse tutors that indicated a decrease in death education, with diploma students receiving a mean of $7.8 \mathrm{hrs}$ of tuition and degree students receiving slightly more at 12.2 hrs. Difficulty in finding appropriately qualified teaching staff is suggested by two thirds of the respondents in LloydWilliams and Field's [19] study as a possible reason for the limited time allocated to the teaching of this topic.

More recently, Dickinson et al. [47] surveyed 66 UK preregistration programmes. Using a questionnaire with a return rate of $79 \%$, they found the average number of teaching hours dedicated to death and dying is now 45 hours. They point to an overall positive improvement claiming that in the UK, palliative care education is "alive and well" in preregistration education, with the caveat that this provision is often "squeezed in" to an already overcrowded curriculum [47, page 167].

But is this significant improvement part of a long-term international trend? The evidence from other countries is contradictory, but reveals more widespread coverage than previously reported. Ferrell et al.s [48] extensive survey of nursing faculties across the US found that the majority provides some level of death education. When respondents $(n=725)$ were asked about adequacy of provision, however, all rated it around 6 on a scale where 0 was "not adequate" and 10 was "very adequate." In Canada, 96\% of the nursing programmes offer "death education content" with an average of 24 hours provided by classroom activities and 36 by clinical practice [46]. However, it appears that in South American countries, such as Argentina, there is virtually no death education in the undergraduate nursing curricula with Mutto et al. [38] and students calling for death education to be given more prominence.

In contrast, writing in the Australian context, Johnson et al.s [30] survey of 39 Deans of Nursing (response rate
$76 \%$ ), found there was little change to the provision of death education in undergraduate nursing curricula over the last 50 years. The authors claim that death education has a minimal and inconsistent presence in Australian undergraduate nursing programmes and that the reform of these is required to enhance practice in the care of dying patients [30]. A more recent publication by Ramjan et al. [49] highlights the introduction of the Palliative Care Curriculum for Undergraduates (PPC4U), a programme that promotes the integration of palliative care content across healthcare education in all Australian universities. While the amount has not been quantified or evaluated, death education, as an integrated core component, is intended to develop end-of-life care capabilities amongst all nursing students [49].

The literature discussed above provides emerging evidence that global efforts to increase the amount of death education in undergraduate curriculum are underway. Inconsistency of findings across studies is difficult to explain with any surety, but it points to issues of interpretation of terms used in survey questions. This may be compounded by low response rates $[19,46]$ or an over estimation of provision $[12,47]$ because only those with an interest in this particular area may have responded to surveys.

\section{Content and Teaching Strategies}

The literature $(N=22)$ suggests that death education varies in content, duration, and design. From a review of US teaching texts, Ferrell et al. [43] identify the following topics which continue to form the basis of the ELNEC programme used by many North American programmes [13, 50, 51]: definitions of palliative care, quality of life, pain and other symptom management, communication, needs of family caregivers, death, ethical and legal issues, and bereavement. The majority of curricula in the UK have been shown to have similar content $[46,47]$. A smaller proportion (86\%) includes spiritual care and only $60 \%$ offer sessions on nutrition and hydration during the dying phase and the use of advanced directives [47]. The literature suggests that death education is comprehensive in relation to the themes covered, but there is a paucity of studies focusing on mental health issues, coping strategies, and care of the deceased.

Dickinson et al. [47] found that a quarter of the UK nursing schools offered a full semester on death education while one third integrated it within other modules across the curriculum. The issue of dedicated versus integrated modules on death education is taken up by O'Connor and Fitzsimmons [52] who debate the merits of both designs. They conclude that irrespective of the approach taken, the critical factor is that learning outcomes are clearly enunciated within curricula and aligned against teaching, learning, and assessment strategies. Other commentators favour separate modules, arguing that any particular topic would, otherwise, be lost in the multiplicity of themes included in the curriculum.

A wide range of teaching methods is used, with the lecture format being the most popular and traditional mode of delivery followed by small group discussions [19, 30, 47]. Case studies, audio-visual material, and self-directed activities tend to augment didactic approaches [47]. While 
role play and journal writing are less popular [30, 53, 54], these methods are thought to promote student reflection and interactive learning [55]. A more innovative approach is "storytelling," whereby patients and carers share their experiences directly with students $[56,57]$. There are also calls for death education to be taught as an interprofessional subject $[56,58,59]$.

The available evidence suggests that teaching within preregistration curricula is predominantly theoretical and that the application of theory to practice is rarely formally assessed $[19,54]$. The reasons for this are unclear but may relate to a lack of suitably skilled staff to teach death education and a shortage of appropriate clinical placements $[13,19,54]$. The most effective approach, however, is thought to be a mix of didactical methods and a combination of multiple topics delivered over an extended period of time rather than stand alone modules. Learning outcomes are thought to be more achievable if teaching is integrated with practical clinical experiences that can be reflected upon $[49,54,60]$. Little consideration seems to have been given to whether teaching strategies should be dependent upon the domain of knowledge being addressed.

A new and emerging literature focuses on the use of e-health technologies to teach death education. A total of 8 studies in the review addressed this topic. Advances in technology have enabled the use of a range of sophisticated human patient simulators from relatively simple task trainers, through low-, medium-, and high-fidelity mannequins equipped with lungs, heart and stomach sounds. In addition, highly complex computerised software programmes have been integrated into suitable mannequins that mimic human physiology and respond appropriately to an intervention by the student. The use of simulation using fidelity mannequins is gaining in popularity and is perceived as an effective teaching method [51, 61].

One example is Gillan et al.'s [62] study of third year nursing students $(n=120)$ in which simulated end-of-life care scenarios involved small groups as well as role play. Students were required to provide end-of-life care using a high-fidelity mannequin in a challenging care scenario which included communicating with the dying patient and family members whose roles were played by students. A total of six simulation sessions were undertaken, video recorded, and played back to students in debriefing sessions with experienced nurse academics. Prior preparation involved lectures and a patient history, both of which helped to set the scene. Evaluations revealed that the majority of students found the care simulation exercises to be a valuable learning tool in helping to link theory to practice, communicating with families of dying patients and they also valued the practical experience of encountering death within a protected environment.

Another example is provided by Fluharty et al.'s [51] study of nursing students $(n=370)$ drawn from four universities that was very similar to that of Gillan et al.s [62] in terms of design and execution, whereby lectures are utilised in preparation for simulation and role play by students. Scripts are given to students who play the roles of either nurse or wife in order to facilitate the flow and direction of the scenario. Small groups of 4-5 students have an hour to complete the simulation exercise of which 20 minutes are allocated for the simulation scenario, 20 minutes for a debriefing and guided reflection session, and 20 minutes to complete four postsimulation questionnaires. The results show that students had significantly enhanced their knowledge in end-of-life care as well as high levels of self-confidence, self-reported communication skills, and satisfaction with the pedagogical approach. In contrast to Gillan et al.'s [62] and Fluharty et al.s [51] broad approach, Smith-Stoner's [61] simulation exercise is focused explicitly on the 30 minute period immediately before and after the death of a patient. It is used to familiarise students and enhance their knowledge about the stages and processes of death. This teaching strategy also encourages students to consider the importance of quality of life in end-of-life care.

In another innovative approach to teaching death education, Kopp and Hanson [50] describe how the use of simulation exercises was enhanced by a board game called "Season of Loss." The game is played by small groups of 4-5 students during a 1-hour lecture session. As the dice is thrown, students move game markers around the board accordingly and land on positions that describe various challenges related to terminal illness; students then have to discuss the issue from their own personal perspective as though it was actually happening to them. The game is complete when the marker lands on the final section called "The end: How would you like it to be?" By using simulation and the board game, Kopp and Hanson [50] found that students develop awareness of the issues related to EOL and encounter realistic challenges typically experienced by the terminally ill. Furthermore, the majority of students felt that they could successfully transfer insights gained from this gaming simulation to real clinical situations and reported that through the guided experiential process and debriefing in small-group discussions, they have become more aware of the losses people suffer. They also had learnt to be more empathetic in their interactions with terminally ill patients.

Advocates of simulation claim that it promotes active and experiential learning, creative thinking, and high-level problem solving $[50,63]$ and it improves clinical skills in a safe, relevant environment [64]. It has also been suggested that simulation supports peer interaction and assists in applying previously learned knowledge bridging the gap between theory and practice [62]. Other studies support simulation as a way to improve clinical judgement and clinical reasoning skills, improving teamwork and communication skills [61, 62], and improving self-confidence [51]. The literature on end-of-life simulation supports the need to provide opportunities in end-of-life nursing care in a clinical setting $[17,51]$ and suggests that experiential learning strategies such as simulation can provide students with the opportunity to explore their own ideas about death and what it means to care for patients who are dying, in a safe and supportive environment $[50,61]$. The increasing popularity of simulations as a teaching strategy can be attributed to technological developments, the reduced availability of clinical placement provision, and an ideological shift in what is considered ethical in practising essential clinical skills. Simulation provides an intense learning experience while allowing learners to practise safely before they perform a procedure in clinical practice. 


\section{Reported Outcomes of Educational Interventions}

The literature relating to evaluation of educational provision for student nurses is limited, with only 5 reporting on educational interventions designed to improve attitudes, 10 on communication interventions, and 6 on clinical skills. Moreover, Brajtman et al. [32] claim that the efficacy of educational interventions is dependent upon educators having expertise in death education. Three studies evaluate combined educational components which use a variety of teaching methods and contain multiple topics including communication, pain, and symptom management [53, 55, 65]. One module includes a hospice placement [53] and another is an extensive companionship programme with few hours allocated to theoretical teaching in accordance with experiential learning theory principles [65]. Both modules use the validated Palliative Care Quiz for Nurses (PCQN) as an evaluation tool. Arber [53] reports a significant increase in knowledge measured immediately after the module, particularly in symptom control and opioid use. In Kwekkeboom et al.'s [65] study, scores for changes in knowledge and attitudes were not statistically significant. However, these studies use very small convenience samples and the results must, therefore, be treated with caution.

Brien et al. [55] argue convincingly for the importance of reflective and experiential activities in preparing students to care for dying patients. When evaluating a mandatory 4-week death education course which interspersed classroom sessions with clinical placements, major differences in perception between students and educators were found. Educators feel that despite the interactive workshops, students demonstrate basic skills and low competence. However, later access to students' reflective journals contradicted the initial perceptions with students demonstrating stronger awareness of end-of-life care, particularly valuing activities involving an introspective and reflective dimension. These findings align with the work of Ferrell et al. [12] who found significant improvement in students' care knowledge and test scores associated with formal theory-based education and the ELNEC curriculum. The ELNEC programme was developed by end-of-life care experts and is considered by some to be "the gold standard" in developing the skills and competencies required to provide quality care $[66,67]$, but little evidence of its impact on patient care is provided [12]. While these results highlight the difficulties nurse educators face in assessing outcomes of experiential and reflective activities, they should not deter others from addressing the affective domain of learning when implementing new programmes of study.

5.1. Attitudes. A number of studies evaluate interventions which seek to positively influence student nurses' attitudes towards the care of the dying that Kennedy et al. [68] identify as essential to improving practice. Mallory [20], for example, explores attitudinal and behavioural changes amongst nurses who have death education as an optional part of their undergraduate programme. Using a quasi-experimental longitudinal design, data is gathered at four points during and after the course. Mallory [20] found a significant difference in the attitudes of nursing students $(n=45)$ who had taken the 6-week course when compared with nursing students $(n=59)$ who had not. The features of "difference" that she identifies relate to an increase in positive attitude towards dying patients and care practices. She comments on the importance of the timing of the palliative care education component, arguing that placing this early in the schedule may prevent students from developing false ideas and assumptions about care of the dying.

Similar outcomes are identified by Frommelt's [69] evaluation of a semester-long death education programme and Barrere et al.s [67] of a module that integrates theory with clinical practice. Both evaluations indicate that students' level of anxiety about death and dying improved. Equivalent results are also reported by Brajtman et al. [32] whose study asked 58 students in their final year of training about caring for terminally ill patients. While the results found that students hold positive attitudes towards dying patients, one third do not feel adequately prepared to care for them. Most of the education courses focusing explicitly on students' attitudes towards death seek to recognise and address patients' psychosocial problems. These studies are, however, underpinned by an assumption that an improved attitude and reduced anxiety towards death are automatically related to better communication and an improved quality of patient care [20, $69,70]$. No evidence of this is provided.

5.2. Communication. Effective communication can help to improve patients' emotional and physical wellbeing and support adjustment to illness [71]. Communication skills are accorded a high priority within pre-registration curricula [47, 54] and are developed in multiple arenas and at all stages in student education. Despite this, a continuing concern relates to the lack of confidence and skills in this area, particularly in the context of end of life care [22].

Studies by Kiger [29], Wong and Lee [72], and Walsh and Hogan [73] found that students find communication with dying patients and bereaved relatives to be challenging and feel more comfortable talking with them on a superficial level. Pfund et al. [74] also report that nurses' distress arises, not so much from patients dying, but from their own self-perceived lack of communication skills. Further evidence for this comes from Cunningham et al. [44], who explore the perceptions of 134 students at the end of their first year of training; students express feelings of fear and inadequacy when communicating with cancer patients and comment on a lack of classroom preparation.

Some studies have looked specifically at outcomes of provision of death education for student nurses, although many are small in scale. Reporting on modules on end-of-life care, both Walsh and Hogan [73] and Thompson [75] suggest that students benefit both personally and professionally from opportunities to communicate and explore their own feelings about death. Yet, difficulties in formally assessing student's reflective accounts have been noted [55]. Turner et al. [56] positively evaluate one-day communication workshops in which carers of terminally ill persons or those recently bereaved, participate. Students are reported as being able 
to communicate with ease and develop listening skills even when carers become emotional or distressed.

Listening skills and empathy are identified as crucial dimensions of communication within therapeutic relationships [60], but studies which evaluate these capabilities are missing from the literature. Students and newly qualified nurses, however, are uncertain of the appropriateness of forming relationships and becoming emotionally involved with patients and their families $[22,76]$. Participants advocate for education that would help them develop strategies for "controlled involvement" [76].

The teaching of communication skills appears to be a key area where theoretical input combined with practice may increase students' confidence and reduce their anxieties $[44,54]$. Promoting choice and offering psychosocial support to patients to help them cope with a range of losses require high levels of sensitive and empathic communication, which, if to be meaningful to patients, has to be responsive to them as individuals. While a high priority is now placed on these skills, this comes with little evaluation of its impact on patients [71].

5.3. Clinical Skills. In relation to clinical skills, the evidence is ambivalent. Cunningham et al. [44], for example, found that students at the end of their first year are less positive about the adequacy of their skills when talking about specific clinical encounters. Over half $(n=85,63 \%)$ say they have nursed patients with cancer whilst on placement, $62 \%$ say they do not feel confident to practice, and $77.6 \%$ consider that they do not have sufficient skills to care for cancer patients. Allchin [22] also explores this issue. She found, however, that experiencing patient deaths strengthens students' clinical skills and supports their professional development.

An elective nursing module designed to strengthen students' clinical skills is evaluated by Brajtman et al. [32]. Results indicate that students have modest knowledge levels, with one-third feeling inadequately prepared to care for dying patients. Students and educators agree that more emphasis on experiential learning throughout the curriculum is needed.

The opportunity to gain clinical experience as a way of developing knowledge and skills is acknowledged [20,76]; however, the evidence suggests that few attempts are made to align clinical placements to theoretical learning [22, 44, $52,54]$. Hospice placements in particular are deemed to offer effective learning opportunities which can enhance students' skills and enable them to care more effectively for dying patients [77]. However, given the numbers involved, it is not feasible to arrange hospice placements for all students. Furthermore, most deaths occur outside such specialist settings and a majority of the students will, post-registration, find themselves working in non-specialist clinical environments [15].

\section{Discussion}

This integrated review set out to explore the published literature that reports on death education within pre-registration nurse education. Death education is a broad term that is used in the context of this paper, to encompass both palliative and end-of-life care. Palliative care is an approach that improves the quality of life of patients facing life-threatening illness while seeking to affirm life and accept death as a normal process [78]. End-of-life care is, therefore, part of the palliative care approach to identify and meet the needs of people who are dying. It is estimated that the majority of people dying from life-threatening conditions do not experience a "good death;" they die without adequate symptom or pain control, and the management of social, psychological, and spiritual concerns $[13,14]$.

Recent policy has on an international level, raised the profile of palliative and end-of-life care, with the aim of increasing access to and improving the quality of care provided to everyone experiencing life-limiting illness. Of all healthcare professionals, nurses are at the forefront of care provision across the lifespan and in almost all healthcare environments including inpatient, outpatient, home care, and hospice settings. Thus, nurses have an essential role in delivering this care and need to be equipped with particular knowledge and skills.

The inadequacy of nurse education is, however, perceived as a barrier to achieving high quality palliative and endof-life care $[22,23,30]$, with this paucity first highlighted almost half a century ago by Quint [28] in her seminal study. Pre-registration and undergraduate nursing curricula have traditionally had a limited emphasis on death and dying, and nurses report feeling unprepared to care for dying patients $[22,24,38]$. In addition, a number of authors have commented on the lack of education provided to nurses in relation to death education $[3,20,22,23,30,72]$.

Preparing future nurses to care for dying patients represents a challenge to nurse educators. Yet, this review of the literature suggests that overall, there has been an increase in the amount of death education within pre-registration curriculum [47]. The recent survey by Dickinson et al. [47] found that the average number of teaching hours dedicated to death education in the UK was 45 hours. This indicates a four-fold increase over the past two decades. Similar increases are also to be found in the USA [48] and Canada [46]. In Australia and Argentina, a minimal and inconsistent approach to the inclusion of death education was indicated. There was little evidence in the literature of many other countries increasing the amount of death education in pre-registration curricula. Nonetheless, recent literature indicates that pre-registration curricula are in the process of changing in response to both research evidence and policy recommendations [13, 23, 49].

In relation to content, the literature indicates that preregistration curricula vary in content and design. Many North American nursing curricula use the ELNEC programme which contains a comprehensive list of topics covered $[13,50,51]$, and this approach is beginning to be adopted by nurse educators throughout Europe [13]. Curricula from the UK and Australia tend to have very similar content $[46,47,49]$. Thus, in terms of the topics covered, the literature indicates comprehensive coverage with the exception of spiritual care, nutrition and hydration, and the use of advanced directives [47]. In addition, there is little evidence of the inclusion in pre-registration nursing curricula of mental 
health issues, organisation of care, teamwork, and bodily care of the deceased.

The literature suggests that teaching tends to take a mainly theoretical approach with the application of theory to practice not formally assessed $[19,54]$. A wide range of teaching strategies are utilised with the most effective approach considered to be traditionaly didactic methods integrated with practical clinical placements and small group discussions. A preference for multiple topics to be delivered over an extended period rather than in isolated stand-alone modules was evident $[49,54,60]$. Arber [53], however, states a preference for separate modules in pre-registration programmes because she claims that the topic would, otherwise, disappear in the multiplicity of themes included in the curriculum. These strategies are augmented with a range of other methods such as case studies, audio-visual material, games, and storytelling [30, 47, 50, 55-57].

Positive learning outcomes of educational interventions were generally reported regardless of topic and whether these were stand alone or integrated modules, but there was little evidence of this leading directly to longer term improvements in patient care. Learning outcomes are thought to be more achievable if teaching is integrated with practical clinical experiences that can be reflected upon $[49,54,60]$. It should be noted, however, that factors other than the intervention itself could potentially influence the outcomes of modules that cannot be readily undertaken in single group pre-and post-training studies. The literature shows that pre-registration curricula also place considerable importance on developing students' communication skills, but again, there was little evidence of how this might have improved patient care [71]. Good communication between nurses and patients underpins high-quality care; this, we would argue, is especially important in end-of-life care.

The evidence for effective development of clinical skills is inconclusive. On the one hand, educators assert that experiential learning strengthens the development of clinical skills $[22,32,38]$, but on the other, students continue to report a lack of confidence and feeling inadequately prepared to care for dying patients $[22,32,44]$. Experiential learning with real patients is nonetheless, considered to be the most effective method for developing clinical skills $[22,55]$.

Given the challenges of appropriate and sufficient clinical placements, it is encouraging to note an increasing body of research that supports the use of technology in nurse education. The literature suggests that end-of-life simulation in particular is a powerful teaching and learning strategy and an effective pedagogical approach to death education [50, 51, 61-63]. While simulations can replace real patients during role play exercises, more information is required on the most effective structure and length of interviews and role play especially for highly emotional scenarios.

\section{Limitations and Further Research}

In this integrative literature review, as a result of stringent inclusion criteria, papers focusing on post-registration continuing education were excluded but could potentially have shed light on the longer term consequences of death education in the pre-registration curriculum. The "grey literature" was not explored and this could potentially lead to publication bias as studies with negative results may not have been published. Furthermore, the meta-analysis was limited to English speaking publications resulting in the possible exclusion of other valuable data.

Another limitation of the study is that data about types of patients involved in the studies considered in the review are not consistently reported, and this feature is, thus, not included in Table 2. In addition, the data quality of some papers was poor, but was included because the information contained therein was deemed to be of value in that it shed light on innovative teaching methods. It is also pertinent to note that evaluation of outcomes of educational components is a complex area with self-report being a frequently used tool of subjective measurement. Furthermore, self-constructed rating scales were sometimes used with small numbers of respondents, where the validity and reliability of instruments were not clear. These factors call into question the objectivity of analysis and results.

Areas of relevance not addressed in the literature include the issue of core/compulsory versus elective participation by students in death education. Also, there has been little work on the ongoing effectiveness of death education on care practice, specifically whether improvements are maintained over time. These areas require further research.

This review did not address the full scope of palliative care education. To do so would involve a review of the literature focusing on post-registration and postgraduate education, as palliative care is increasingly being regarded as a specialist area of clinical practice [36]. We suggest, however, that there is a need for a similar review of the literature covering these areas of nurse education.

\section{Conclusion}

Reviewers of death education for nurses have over the last two decades, consistently cited inadequacies of provision. However, this integrative literature review provides emerging evidence that global efforts to integrate and increase the amount and content of death education in undergraduate curriculum are underway. There is evidence too of significant innovation in teaching practice and an increasing use of technology and simulation to effectively develop clinical skills. In countries where death education is not integrated into the undergraduate pre-registration curricula, students are ill equipped with the necessary skills and knowledge to care for dying patients, and this has implications for the quality of future care provision [3, 24, 38].

Demographic trends suggest that in the near future, an increasing number of people will require palliative and endof-life care. As Kellehear [79] contends, it is this category of people for whom palliative care has not hitherto been available that may, in the future, be the beneficiary of greater levels of death education. Thus, nurses internationally are encountering increasing numbers of dying patients and it is essential that they feel adequately prepared to provide the required care. 
Although pre-registration curricula have changed in response to research evidence and policy recommendations $[12,33]$, authors continue to claim that more emphasis on death education is needed [22-24, 32], with perceived gaps in death education evident across all types of nurse education programmes, undergraduate, graduate, and as part of continuing professional development [80]. It is possible that these gaps are simply a result of educators not writing and reporting on the developments in their own programmes. Educators should be encouraged to follow the example set by Ramjan et al.s [49], Kopp and Hanson [50], and Gillan et al. [62], of sharing experiences of developing and implementing new programmes about death education. Only then can we learn from each other and share examples of best practice.

Given the reports of the difficulties many nurses experience in dealing with death in non-specialist care settings, it is reasonable to ask whether we can ever adequately prepare nurses to deal with death. One measure of effective death education provision is that cited by Dickinson [77, page 715] who argues that if "at the end of nursing school students feel comfortable educating the patient and family about the dying process, are ready to respond to patients who request assistance in dying, are ready to break bad news to a patient and family, then these professional programmes will have come a long way towards educating students about end-oflife issues."

\section{Conflict of Interests}

The authors declare that there is no conflict of interests regarding the publication of the paper.

\section{References}

[1] World Health Organization, National Cancer Control Programmes: Policies and Guidance, WHO, Geneva, Switzerland, 2002.

[2] C. Centeno, "Latest report from the EAPC task force on the development of palliative care in Europe," European Journal of Palliative Care, vol. 13, no. 4, pp. 149-151, 2006.

[3] T. Lynch, D. Clark, C. Centeno et al., "Barriers to the development of palliative care in Western Europe," Palliative Medicine, vol. 24, no. 1, pp. 812-819, 2010.

[4] G. Hirsch, "SFAP: France is witnessing major developments in palliative care," European Journal of Palliative Care, vol. 16, no. 2, pp. 100-101, 2009.

[5] Department of Health, End of Life Strategy: Promoting High Quality Care for All Adults at the End of Life, The Stationery Office, London, UK, 2008.

[6] Scottish Government, Living and Dying Well, Scottish Government Health Department, Edinburgh, UK, 2008.

[7] Health Canada, "Canadian strategy on palliative and end of life care," final report, 2007.

[8] Health Care Guidelines: Palliative Care, Institute for Clinical Systems Improvement, Minnesota, Minn, USA, 2009.

[9] Clinical Practice Guidelines for Quality Palliative Care, National Consensus Project for Quality Palliative Care, Pittsburgh, Pa, USA, 2nd edition, 2009.

[10] Hospice Friendly Hospitals: Draft Quality Standards for End of Life Care in Hospitals, Irish Hospice Foundation, Dublin, Ireland, 2009.
[11] Palliative Care Australia, "National Report on Palliative Care in Australia, Canberra, Australia, 2009”.

[12] B. R. Ferrell, R. Virani, M. Grant et al., "Evaluation of the endof-life nursing education consortium undergraduate faculty training program," Journal of Palliative Medicine, vol. 8, no. 1, pp. 107-114, 2005.

[13] J. A. Paice, B. R. Ferrell, N. Coyle, P. Coyne, and M. Callaway, "Global efforts to improve palliative care: the international endof-life nursing education consortium training programme," Journal of Advanced Nursing, vol. 61, no. 2, pp. 173-180, 2008.

[14] L. Radbruch, L. de Lima, D. Lohmann, E. Gwyther, and S. Payne, "The Prague Charter: urging governments to relieve suffering and ensuring the right to palliative care," Palliative Medicine, vol. 27, no. 2, pp. 101-102, 2012.

[15] Palliative Care for Non-Cancer Patients, University Press, Oxford, UK, 2001, Edited by J. M. Addington-Hall and I. J. Higginson.

[16] World Health Organization, World Health Statistics, World Health Organization, Geneva, Switzerland, 2012.

[17] K. Leighton and J. Dubas, "Simulated death: an innovative approach to teaching end-of-life care," Clinical Simulation in Nursing, vol. 5, no. 6, pp. e223-e230, 2009.

[18] C. Gibbons, M. Dempster, and M. Moutray, "Stress, coping and satisfaction in nursing students," Journal of Advanced Nursing, vol. 67, no. 3, pp. 621-632, 2011.

[19] M. Lloyd-Williams and D. Field, "Are undergraduate nurses taught palliative care during their training?" Nurse Education Today, vol. 22, no. 7, pp. 589-592, 2002.

[20] J. L. Mallory, "The impact of a palliative care educational component on attitudes toward care of the dying in undergraduate nursing students," Journal of Professional Nursing, vol. 19, no. 5, pp. 305-312, 2003.

[21] J. M. Deffner and S. K. Bell, "Nurses' death anxiety, comfort level during communication with patients and families regarding death, and exposure to communication education: a quantitative study," Journal for Nurses in Staff Development, vol. 21, no. 1, pp. 19-23, 2005.

[22] L. Allchin, "Caring for the dying: nursing student perspectives," Journal of Hospice and Palliative Nursing, vol. 8, no. 2, pp. 112$117,2006$.

[23] E. M. Mutto, A. Errázquin, M. M. Rabhansl, and M. J. Villar, "Nursing education: the experience, attitudes, and impact of caring for dying patients by undergraduate argentinian nursing students," Journal of Palliative Medicine, vol. 13, no. 12, pp. 14451450, 2010.

[24] J. Cui, F. Shen, X. Ma, and J. Zhao, "What do nurses want to learn from death education? A survey of their needs," Oncology Nursing Forum, vol. 38, no. 6, pp. e402-e408, 2011.

[25] R. Becker, "What future for palliative care education?" International Journal of Palliative Nursing, vol. 19, no. 3, pp. 107-108, 2013.

[26] "Nursing and Midwifery Council," Statutory Competenciesadult nursing, 2010, http://bit.ly/Y0dybh.

[27] Nursing and Midwifery Council, "Standards for education, Standard 7. Requirement R7 1. 3," 2010, http://bit.ly/Z5Ax6g.

[28] J. C. Quint, The Nurse and the Dying Patient, Macmillan, New York, NY, USA, 1967.

[29] A. M. Kiger, "Student nurses' involvement with death: the image and the experience," Journal of Advanced Nursing, vol. 20, no. 4, pp. 679-686, 1994. 
[30] A. Johnson, E. Chang, and L. O’Brien, "Nursing the dying: a descriptive survey of Australian undergraduate nursing curricula," International Journal of Nursing Practice, vol. 15, no. 5, pp. 417-425, 2009.

[31] F. Aulino and K. Foley, "Professional education in end-of-life care: a US perspective," Journal of the Royal Society of Medicine, vol. 94, no. 9, pp. 472-476, 2001.

[32] S. Brajtman, K. Higuchi, and M. A. Murray, "Developing meaningful learning experiences in palliative care nursing education," International Journal of Palliative Nursing, vol. 15, no. 7, pp. 327-331, 2009.

[33] G. Carr, "Changes in nurse education: delivering the curriculum," Nurse Education Today, vol. 28, no. 1, pp. 120-127, 2008.

[34] L. Salminen, M. Stolt, M. Saarikoski, A. Suikkala, H. Vaartio, and H. Leino-Kilpi, "Future challenges for nursing education: a European perspective," Nurse Education Today, vol. 30, no. 3, pp. 233-238, 2010.

[35] J. Hegarty, E. Walsh, C. Condon, and J. Sweeney, "The undergraduate education of nurses: looking to the future," International Journal of Nursing Education Scholarship, vol. 6, no. 1, article 17, 2009.

[36] J. K. Skilbeck and S. Payne, "End of life care: a discursive analysis of specialist palliative care nursing," Journal of Advanced Nursing, vol. 51, no. 4, pp. 325-334, 2005.

[37] Department of Health, End of Life Care Strategy: Second Annual Report, The Stationery Office, London, UK, 2010.

[38] E. Mutto, M. Cantoni, M. Rabhansl, and M. Villar, "A perspective of end-of-life care education in undergraduate medical and nursing students in Buenos Aires, Argentina," Journal of Palliative Medicine, vol. 15, no. 1, pp. 93-98, 2012.

[39] C. L. Russell, "An overview of the integrative research review. Progress in transplantation," 2005, http://natco.metapress.com/ content/0n13660r26g725kj.

[40] H. M. Cooper, Synthesizing Research: A Guide For Literature Reviews, Sage, Thousand Oaks, Calif, USA, 3rd edition, 1998.

[41] R. Whittemore and K. Knafl, "The integrative review: updated methodology," Journal of Advanced Nursing, vol. 52, no. 5, pp. 546-553, 2005.

[42] A. Bryman, Social Research Methods, Oxford University Press, Oxford, UK, 2008.

[43] B. Ferrell, R. Virani, and M. Grant, "Analysis of end-of-life content in nursing textbooks," Oncology Nursing Forum, vol. 26, no. 5, pp. 869-876, 1999.

[44] S. M. Cunningham, G. Copp, B. Collins, and M. Bater, "Preregistration nursing students' experience of caring for cancer patients," European Journal of Oncology Nursing, vol. 10, no. 1, pp. 59-67, 2006.

[45] D. Field and C. Kitson, "Formal teaching about death and dying in UK nursing schools," Nurse Education Today, vol. 6, no. 6, pp. 270-276, 1986.

[46] B. Downe-Wamboldt and D. Tamlyn, "An international survey of death education trends in faculties of nursing and medicine," Death Studies, vol. 21, no. 2, pp. 177-188, 1997.

[47] G. E. Dickinson, D. Clark, and M. Sque, "Palliative care and end of life issues in UK pre-registration, undergraduate nursing programmes," Nurse Education Today, vol. 28, no. 2, pp. 163-170, 2008.

[48] B. Ferrell, R. Virani, M. Grant, P. Coyne, and G. Uman, "Dignity in dying," Nursing Management, vol. 31, no. 9, pp. 52-57, 2000.

[49] J. M. Ramjan, C. M. Costa, L. D. Hickman, M. Kearns, and J. L. Phillips, "Integrating palliative care content into a new under- graduate nursing curriculum: the University of Notre Dame, Australia-Sydney experience," Collegian, vol. 17, no. 2, pp. 8591, 2010.

[50] W. Kopp and M. A. Hanson, "High-fidelity and gaming simulations enhance nursing education in end-of-life care," Clinical Simulation in Nursing, vol. 8, no. 3, pp. e97-e102, 2012.

[51] L. Fluharty, A. S. Hayes, L. Milgrom et al., "A multisite, multiacademic track evaluation of end-of-life simulation for nursing education," Clinical Simulation in Nursing, vol. 8, no. 4, pp. e135e143, 2012.

[52] S. J. O'Connor and D. Fitzsimmons, "Embedding cancer care within pre-registration nurse education programmes: policy, practice and opportunities for change," European Journal of Oncology Nursing, vol. 9, no. 4, pp. 341-350, 2005.

[53] A. Arber, "Student nurses' knowledge of palliative care: evaluating an education module," International Journal of Palliative Nursing, vol. 7, no. 12, pp. 597-603, 2001.

[54] M. Wallace, S. Grossman, S. Campbell, T. Robert, J. Lange, and J. Shea, "Integration of end-of-life care content in undergraduate nursing curricula: student knowledge and perceptions," Journal of Professional Nursing, vol. 25, no. 1, pp. 50-56, 2009.

[55] L.-A. Brien, A. Legault, and N. Tremblay, "Affective learning in end-of-life care education: the experience of nurse educators and students," International Journal of Palliative Nursing, vol. 14, no. 12, pp. 610-614, 2008.

[56] P. Turner, F. Sheldon, C. Coles et al., "Listening to and learning from the family carer's story: an innovative approach in interprofessional education," Journal of Interprofessional Care, vol. 14, no. 4, pp. 387-395, 2000.

[57] M. Schwartz and A. Abbott, "Storytelling: a clinical application for undergraduate nursing students," Nurse Education in Practice, vol. 7, no. 3, pp. 181-186, 2007.

[58] S. M. Schim and R. Raspa, "Crossing disciplinary boundaries in end-of-life education,” Journal of Professional Nursing, vol. 23, no. 4, pp. 201-207, 2007.

[59] World Health Organization, Framework for Action on Interprofessional Education and Collaborative Practice, WHO, Geneva, Switzerland, 2010.

[60] M. Adriaansen and T. van Achterberg, "The content and affects of palliative care courses for nurses: a literature review," International Journal of Nursing Studies, vol. 45, pp. 471-485, 2008.

[61] M. Smith-Stoner, "Using high-fidelity simulation to educate nursing students about end-oj-life care," Nursing Education Perspectives, vol. 30, no. 2, pp. 115-120, 2009.

[62] P. Gillan, G. Paramenter, P. van der Riet, and S. Jeong, "The experience of end of life care simulation at a rural Australian University," Nurse Education Today, vol. 33, no. 11, pp. 1435-1439, 2013.

[63] C. A. Hamilton, "The simulation imperative of end-of-life education," Clinical Simulation in Nursing, vol. 6, no. 4, pp. e131e138, 2010.

[64] A. Hope, J. Garside, and S. Prescott, "Rethinking theory and practice: pre-registration student nurses experiences of simulation teaching and learning in the acquisition of clinical skills in preparation for practice," Nurse Education Today, vol. 31, no. 7, pp. 711-715, 2011.

[65] K. L. Kwekkeboom, C. Vahl, and J. Eland, "Impact of a volunteer companion program on nursing students' knowledge and concerns related to palliative care," Journal of Palliative Medicine, vol. 9, no. 1, pp. 90-99, 2006. 
[66] J. M. Kurz and E. R. Hayes, "End of life issues action: impact of education," International Journal of Nursing Education Scholarship, vol. 3, no. 1, article 18, 2006.

[67] C. C. Barrere, A. Durkin, and S. LaCoursiere, "The influence of end-of-life education on attitudes of nursing students," International Journal of Nursing Education Scholarship, vol. 5, article 11, 2008.

[68] S. Kennedy, J. Seymour, K. Almack, and K. Cox, "Key stakeholders' experiences and views of the NHS End of Life Care Programme: findings from a national evaluation," Palliative Medicine, vol. 23, no. 4, pp. 283-294, 2009.

[69] K. H. Frommelt, "Attitudes toward care of the terminally ill: an educational intervention," The American Journal of Hospice and Palliative Care, vol. 20, no. 1, pp. 13-22, 2003.

[70] E. Wessel and D. Rutledge, "Home care and hospice nurses' attitudes toward death and caring for the dying," Journal of Hospice and Palliative Nursing, vol. 7, no. 4, pp. 212-218, 2005.

[71] C. McCabe, "Nurse-patient communication: an exploration of patients' experiences," Journal of Clinical Nursing, vol. 13, no. 1, pp. 41-49, 2004.

[72] F. Wong and W. Lee, "A phenomenological study of early nursing experiences in Hong Kong," Journal of Advanced Nursing, vol. 31, no. 6, pp. 1509-1517, 2000.

[73] S. Walsh and N. Hogan, "Oncology nursing education: nursing students' commitment of "Presence" with the dying patient and the family," Nursing Education Perspectives, vol. 24, no. 2, pp. 8690, 2003.

[74] R. Pfund, P. Dawson, R. Francis, and B. Rees, "Learning how to handle emotionally challenging situations: the context of effective reflection," Nurse Education in Practice, vol. 4, no. 2, pp. 107-113, 2004.

[75] G. T. Thompson, "Effects of end-of-life education on baccalaureate nursing students," AORN journal, vol. 82, no. 3, pp. 434440, 2005.

[76] J. B. Hopkinson, C. E. Hallett, and K. A. Luker, "Everyday death: how do nurses cope with caring for dying people in hospital?" International Journal of Nursing Studies, vol. 42, no. 2, pp. 125133, 2005.

[77] G. E. Dickinson, "End-of-life and palliative care issues in medical and nursing schools in the United States," Death Studies, vol. 31, no. 8, pp. 713-726, 2007.

[78] J. H. Watts, Death Dying and Bereavement, Issues for Practice, Dunedin Academic Press, Edinburgh, UK, 2010.

[79] A. Kellehear, A Social History of Dying, Cambridge University Press, Cambridge, UK, 2007.

[80] K. R. White and P. J. Coyne, "Nurses' perceptions of educational gaps in delivering end-of-life care," Oncology Nursing Forum, vol. 38, no. 6, pp. 711-717, 2011. 


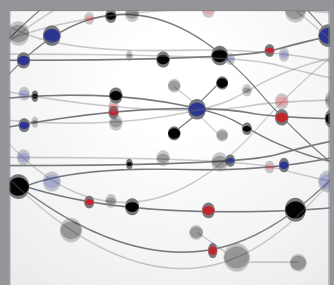

The Scientific World Journal
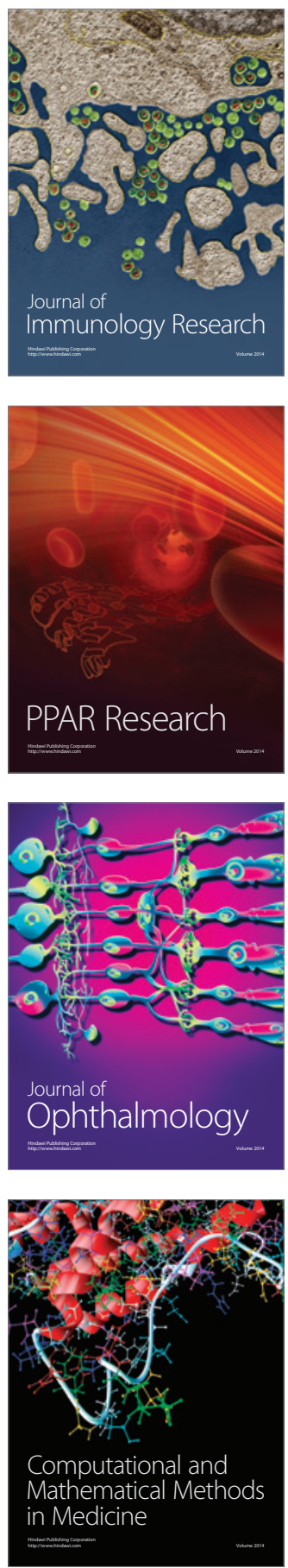

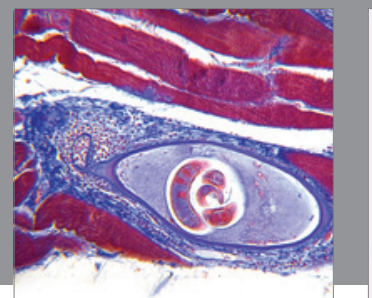

Gastroenterology

Research and Practice
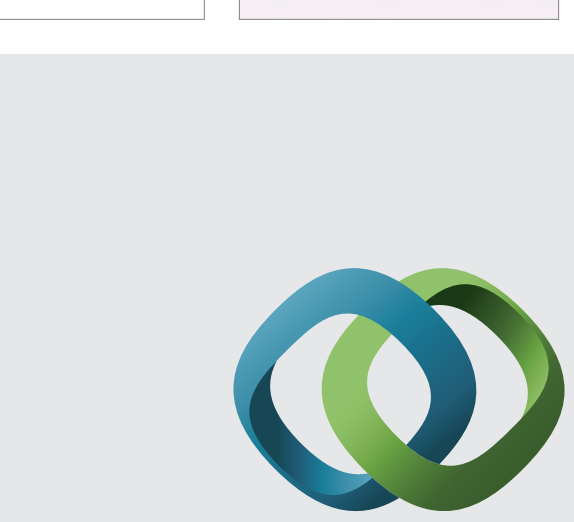

\section{Hindawi}

Submit your manuscripts at

http://www.hindawi.com
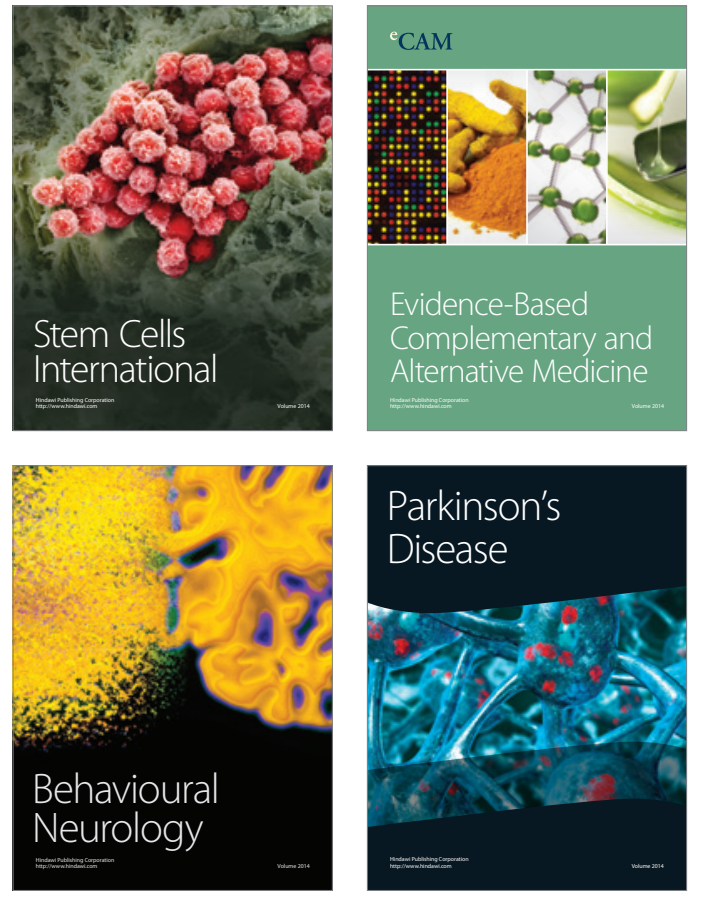
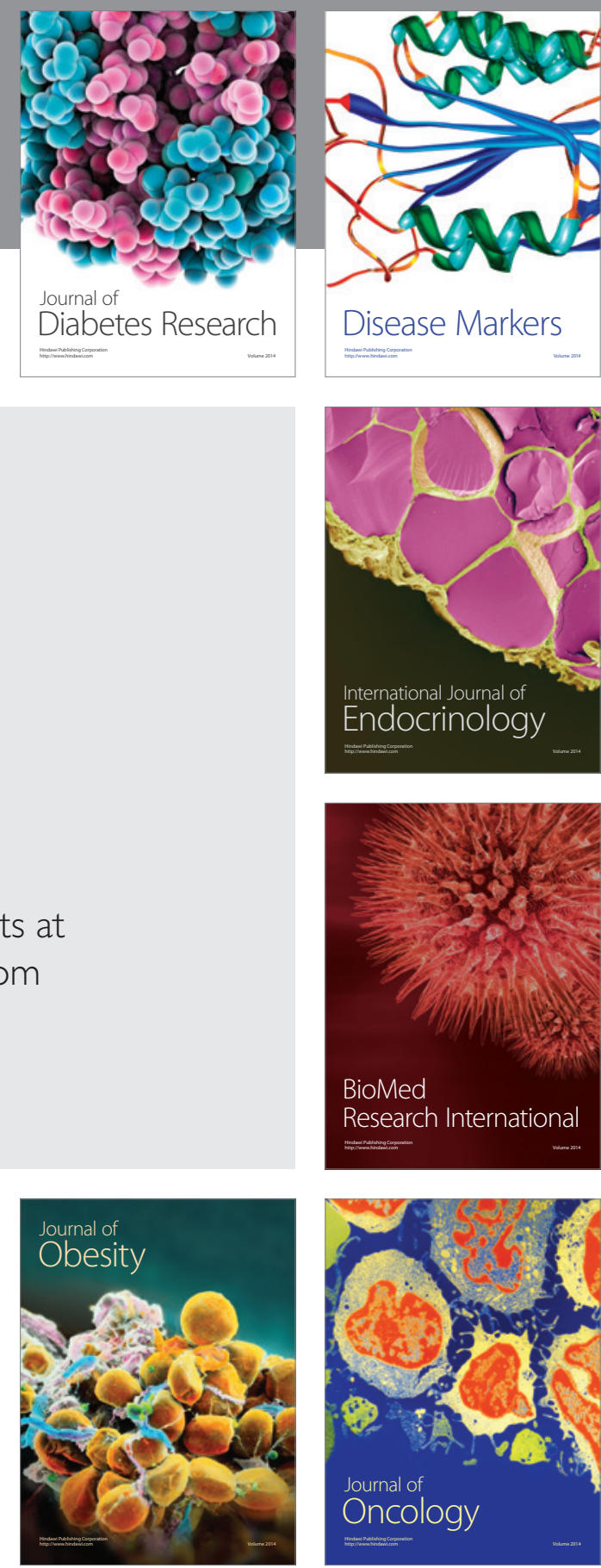

Disease Markers
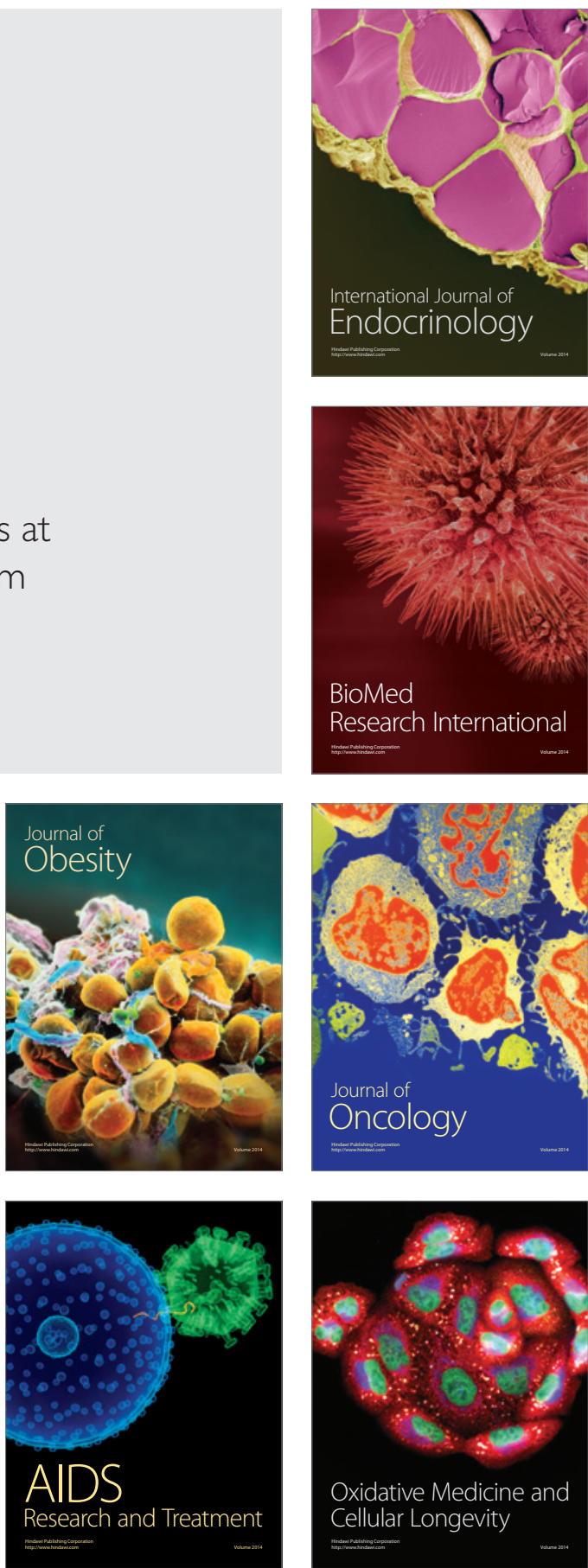